\title{
From sports to science: Designing sports products to experience science and engineering
}

Ruba Ali, Jolly Bhadra, Nitha Siby, Dr. Noora Al-Thani

\section{Introduction}

Sports is an imminent promoter of social integration and economic development in various cultural political and geographic contexts and vitalized as a beacon of pride for numerous countries in the Middle East. Given sports' proven competence to motivate, lead, engage and retain youth in public programs, it can reach out to them and appeal them to school or aid them for the workplace. Validating facts have manifested projects that implement sports as a vehicle abetting the youth to cultivate skills for development alongside preventing crime and reducing risk in vulnerable adolescents, developing social and civic capital, attributing development outcomes as stated earlier. Fisher et al. states that sports is an attractive element in high school background to many students (Fisher, Juszczak, \& Friedman, 1996). Our research on the program is constructed rooting from sports, considering the favors of the population in Qatar (Brannagan, \& Giulianotti, 2014). Qatar has continually been in the limelight of International sports community in the recent years owing to its huge investments, commitments and aspirations in the sports industry (Amara, 2005). Oatar and its socio-economic inclination towards sports has always motivated the implementation of sports driven programs and resultantly, leading us to construct workshop for secondary students, offering STEM activites. Moreover, studies by Choi \& Sang (1997) range of disciplines favored by students. They also emphasize the benefits of constructing real situations or "Problems" in the sports driven activities to achieve aspects such as curiosity, relevance to their personal goals, effective peer collaboration and the simple relation between scientific context in everyday activities.

\section{Objectives}

The program objective was to derive the exceptional dispositions and competences in secondary students' creative innovation and reasoning skills, specifically deductive reasoning and critical thinking. The learning environment and ambience set in the background of sports materials and challenges has the instigating factor of attracting the secondary youth of Qatar. Implementing sports as a vehicle for familiarizing scientific concepts, the program provides access to the latest strategies in promoting science process skills. The program also successfully reach out to students in diverse learning approaches, strengthening their knowledge in science and engineering applications by engaging them in a creative learning environment.

\section{Experimental Method}

The 3-month tenure of the annually organized SIS program is addressed as a cycle. For the curren study, we have considered 5 cycles that took place for consecutive years from 2012 to 2017 , witnessing 248 participants of grade 10 and 11, from 15 public schools. The participant students, both 136 males and 112 females in groups of 3 or 4, were provided with a STEM workshop in either of the topics, concrete or sports materials. The students achieve the essential scientific information on the diverse requisites for designing a sports product like concrete bowling ball, concrete boat, baseball and golf ball. The products after completion will undergo evaluation in the presence of external examiners that includes sports specialist, industrialists and Qatar University faculty mentors. The students are also assessed for their oratory and communication skills in product presentation, in addition to their designed products.

\section{Results and Discussion}

The sports based program has conferred productive insight on the development of students' attitude in STEM fields and careers. The course has positively influenced the aesthetic and intellectual development of participant students as they successfully completed designing their sports products. The sports driven STEM workshop week witnessed active participation of students, engaging them in diverse fun filled activities generating research, inquiry, problem solving, logical reasoning and creativity. The four sports products accomplished by the student groups were distinctly analyzed and the results were drawn to address their journey during the program. Moreover, their experience in accomplishing the challenge also clearly displayed their familiarization of STEM curriculum, aiding to the research objective.
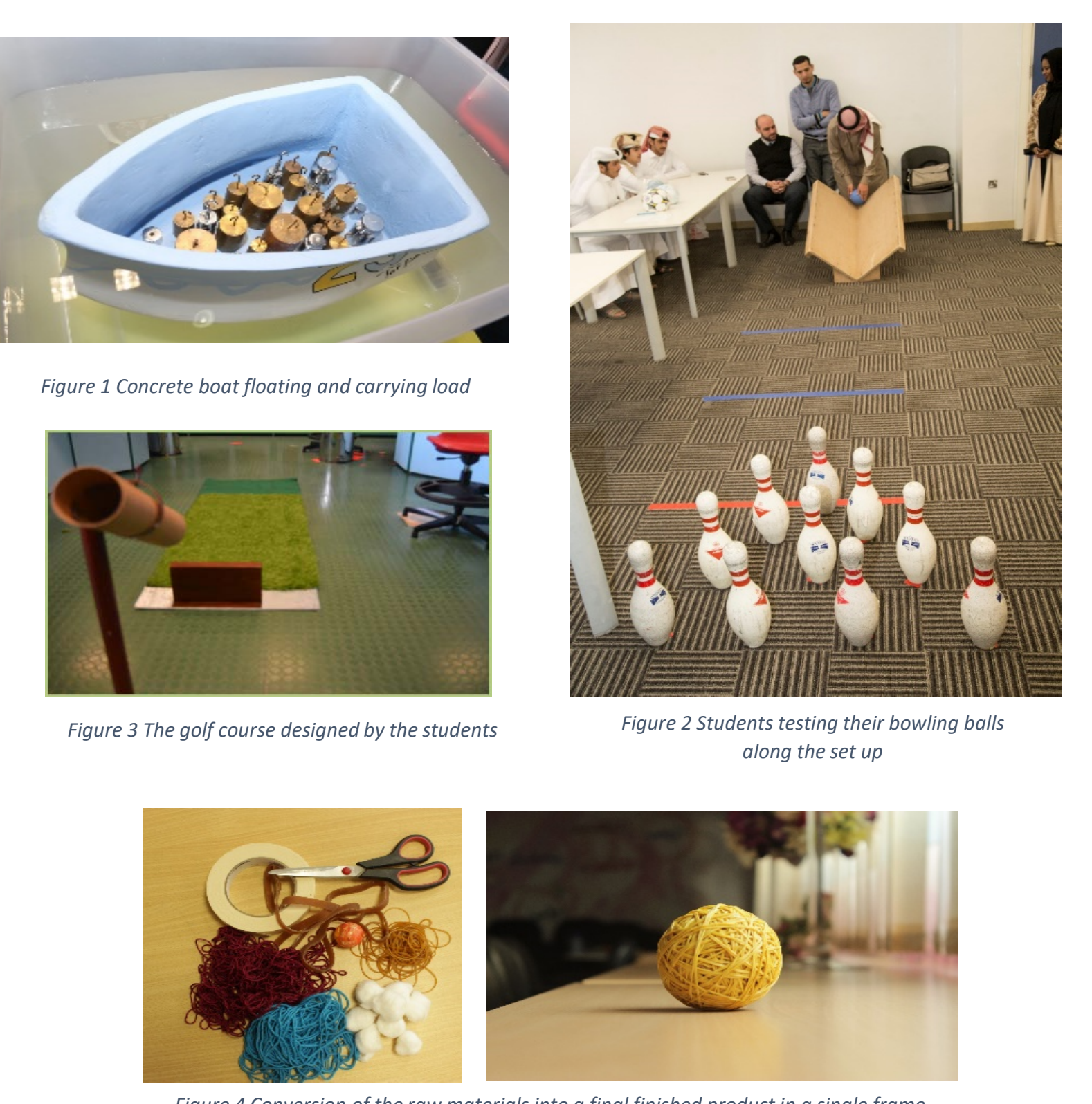

A 2-day conference was organized on the last day of the program, to display and examine the fina products of the students from all the participant schools in the presence of judging panel holding eminent leaders from different STEM driven industries. During the evaluation, the students faced rigorous process of assessment implying their quality in organization/planning of the project, implementation of research methodology, critical thinking and efficiency of creative collaboration. The students were increasingly vocal about their accomplishments as they replied to the queries posted by the judging panel, thereby exhibiting their competences that paved for their cognitive development.

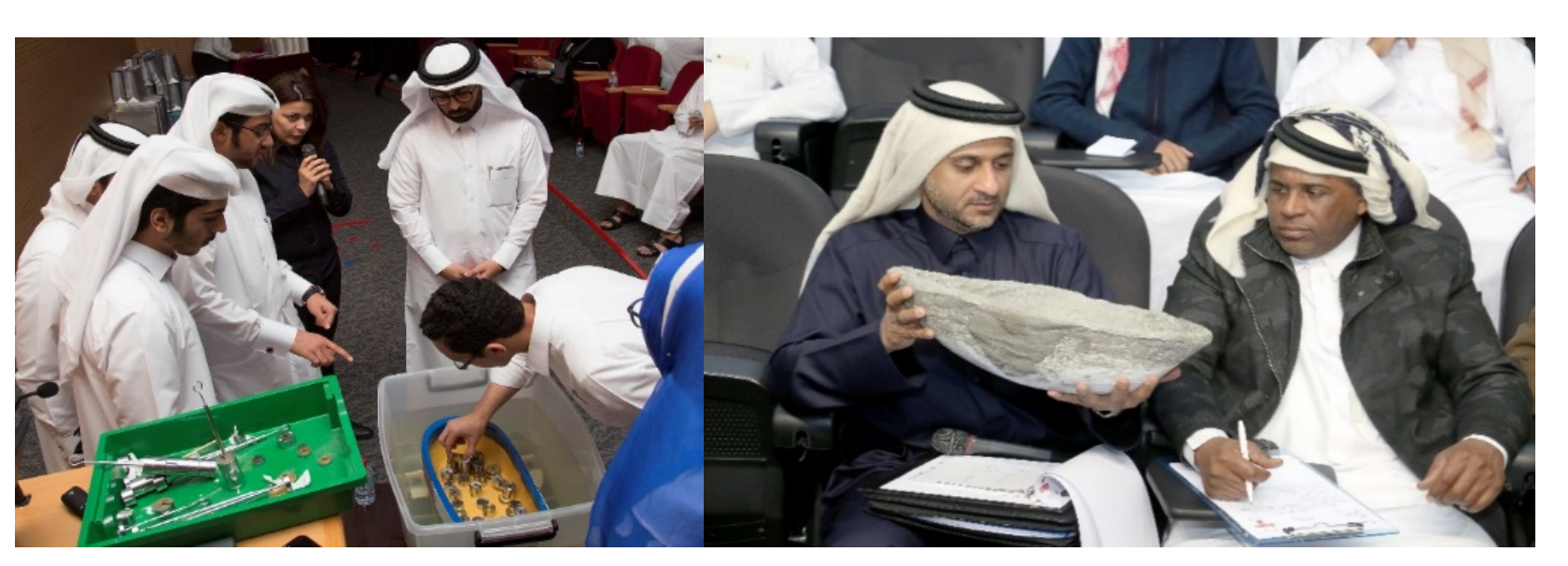

Quantitative analysis of the course was successfully performed by conducting surveys before and after the program. The study clearly emphasized the augmented rate of enthusiasm in students for interactive STEM curriculum. They showed significant increase in their general attitudes about science pursuits and in their skills of scientific reasoning.

Table 1. SIS cycles by t test analysis ( $\mathrm{n}=248)$.
\begin{tabular}{|l|c|c|c|c|c|c|}
\hline Cycle & \multicolumn{3}{|c|}{ Statistics } & \multicolumn{3}{c|}{ Samples test } \\
\cline { 2 - 7 } & Participants N & $\begin{array}{c}\text { Pretest Mean } \\
(\text { SD) }\end{array}$ & $\begin{array}{c}\text { Posttest Mean } \\
\text { (SD) }\end{array}$ & $\begin{array}{c}\text { Mean Diff } \\
(\text { SD) }\end{array}$ & t Value & $p$ Value \\
\hline 1 st & 51 & $3.07(.932)$ & $3.79(.865)$ & $.730(1.185)$ & 4.4 & 0.000 \\
\hline 2 nd & 56 & $3.38(1.205)$ & $3.98(1.032)$ & $.603(1.680)$ & 2.68 & 0.01 \\
\hline 3rd & 35 & $2.98(.570)$ & $3.81(.900)$ & $.836(.889)$ & 5.56 & 0.000 \\
\hline 4th & 52 & $3.46(.865)$ & $3.66(.913)$ & $.202(1.195)$ & 1.22 & 0.229 \\
\hline 5 th & 54 & $2.31(.746)$ & $3.03(.693)$ & $.722(.757)$ & 7.02 & 0.000 \\
\hline
\end{tabular}

\section{Summary and Future Directions}

Sports is often addressed as an inciting subject for the high school students in piquing thei interest in different domains of growth and development. Diverse programs employing sports as vehicle to reach out to the students, provide insights to the effective strategies adopted in engaging youth to enhance their physical, cognitive and emotional development. The student community has flaunted limitations in inclining towards STEM fields and aspirations, thereby driving the educators across the globe to brainstorm copious approaches to tackle the dilemma. Bulding the understanding in students on the everyday connection to STEM is critical to encouraging them to aspire careers in these fields. One of the constuctive methods in engaging aplicarlo applications. Despite the greater emphasis on science as fundamental asset for Qatar's future knowledge society, the results demonstrating the students' cognitive development have been diminishing. The Qatari students also lagged behind in International test scores on mathematics and science in spite of greater expectations. Subsequently the requisite to introduce out of school programs that assisted them in correlating the learning context to real life challenges or environment was aroused. Moreover, similar programs plays a critical role in persuading students to improve their attitudes and performance in scientific subject. This led to the implementation of an out of school sports based STEM program that was exercised through scientific workshops and The pogram was suctions. (a) Qatari students by familarizing them with the engheering design process through sports product development. The program was successful in exploiting the students' interest in sports to engage them in an effective, hands-on and fun approach in learning design technology. The students, much often to the surprise of the facilitators, displayed high levels of reasoning skills and creative collaboration as they solved different challenges that arose during the sports product construction. A statistical analysis of the pre-post questionnaires also successfully interpreted the improvement in their attitudes. However, the program is limited for its competence in providing the positive student outcomes in terms of their performance in international assessment scales. Our future research will align towards analyzing the students competences based on their performance in International platform.

\section{Acknowledgements}

We are deeply grateful to the students of the public secondary schools for their enthusiastic participation in the study. We also thank Dr. Nesibe Gozde Ozerkan, Oatar University and Oatar University - Young Scientists Center for supporting the study. Moreover, we also thank Ras Laffan Industrial City-Community Outreach program and partners, UNESCO and Qatar Nationa Commission for Education, Culture and Science in supporting us for the effective implementation of the study.

\section{References}

Amara, M. (2005). 2006 Qatar Asian Games: A 'modernization'project from above? Sport in society, 8(3), 493-514.

2. Brannagan, P. M., \& Giulianotti, R. (2014). Qatar, global sport and the 2022 FIFA world cup. In Leveraging Legacies from Sports Mega-Events: Concepts and Cases (pp. 154-165). Palgrave Pivot, London.

3. Choi, J., Song, J. (1996) Students' preferences for different contexts for learning science. Research in Science Education 26, 341-352. https://doi.org/10.1007/BF02356944 